Information about the authors: Alevtina A. Kolosova - PhD in history, associate professor of Mass Communication Department of Peoples' Friendship University of Russia

e-mail:Kolosova-aa@,rudn.ru

Information about the authors: Natalia V. Poplavskaya - PhD in Philology, lecturer of Mass Communication Department of Peoples' Friendship University of Russia, Deputy Dean for International Relations, Philological Faculty

e-mail:Poplavskaya-nv@rudn.ru

Сведения об авторах: Колосова А.А. - доктор исторических наук, ассоциированный профессор департамента массовых коммуникаций Российского университета дружбы народов, РФ. Москва, Россия.

e-mail:olosova-aa@rudn.ru

Сведения об авторах: Поплавская Н.В. - доктор филологии, лектор департамента массовых коммуникаций Российского университета дружбы народов, РФ. Москва, Россия.

e-mail:Poplavskaya-nv@rudn.ru

DOI:

\title{
CINEMA AND FILM CRITIC: MEDIAPRACTICS IN DISCOVERING OF THE MEAN DOMINANT
}

\author{
Ludmila Sayenkova-Melnitskaya \\ Candidat of Philological Sciences, Associate Professor \\ Belorussian State University \\ (Minsk, Belarus) \\ e-mail: sayenkova@gmail.com
}

\begin{abstract}
Since its inception, cinema has been one of the most popular forms of art, which, on the one hand, captures, and on the other hand, affects the formation of socio-cultural codes.Simultaneously with the appearance of film originated and film critics, which in itself is a unique fact in the history of art.The cultural significance of film criticism as a special kind of creative activity is determined. Different variants in the presentation of cinema art, formed in different historical periods, are analyzed.Different types of discursive practices of film criticism manifested in the media are considered. The attention is focused on the fact that the most important purpose of film criticism is the representation of value meanings imprinted in the work of cinema.The method of comparative and system-integral analysis reveals the facts of discrepancy between the meanings of screen works and the author's intentions, which are reflected in the critical texts.
\end{abstract}

Keywords. Cinema, film criticism, media, analysis, senses

\section{КИНО И КИНОКРИТИКА: МЕДИАПРАКТИКИ В РАСКРЫТИ СМЫСЛОВЫХ ДОМИНАНТ}

\author{
Людмила Саенкова-Мельницкая \\ Кандидат филологических наук, доцент \\ Белорусский государственный университет \\ (Минск, Беларусь) \\ e-mail: sayenkova@gmail.com
}

\begin{abstract}
Аннотация. С момента своего появления кино является одним из наиболее востребованных видов искусства, которое, с одной стороны, запечатлевает, а с другой стороны, влияет на формирование социокультурных кодов. Одновременно с возникновением кино возникла и кинокритика, что само по себе является уникальным фактом в истории искусства. Определяется культурологическая значимость кинокритики как особого вида творческой деятельности.Анализируются вариативные подходы в презентации киноискусства, сложившиеся в разные исторические периоды. Рассматриваются разные виды дискурсивных практик кинокритики, проявившихся в медиасреде. Акцентируется внимание на том, что самым главным предназначением кинокритики является представление ценностных смыслов, запечатленных в произведении киноискусства. Методом сопоставительного и системно-целостного анализа раскрываются факты несоответствия смыслов экранных произведений авторским интенциям, запечатленным в кинокритических текстах.
\end{abstract}

Ключевые слова. Кино, кинокритика, медиасреда, анализ, смыслы

ВВЕДЕНИЕ. Кинокритика возникла одновременно с показом первых фильмов, что в истории искусства является беспрецедентным фактом. Восторженные анонсы, сопровождавшие первые сеансы и запечатлевшие радость узнавания реальной действительности, зафиксировали гедонистический период в развитии кинокритики. С приобретением кино своего языка, постепенным развитием и усложнением художественной образности экранного зрелища от кинокритики потребовалось не просто выразить удивление от того, как, 
например, «двое малюток, сидя рядом в детских креслах, ссорятся, и один из них плачет», или как «из вагона выходят пассажиры, суетятся встречающие», или как «вино разливается по стаканам, пьется» (Zorkaya 1976), а раскрыть, перевести на язык массовой публики содержательные смыслы, облеченные в художественные образы. Кинокритика, по сути, и есть особый вид творческой практики, предлагающий массовой, и в то же время подготовленной аудитории свой вариант прочтения запечатленных в экранном произведении смыслов, а вместе с этим и вариант раскрытия уникального художественного киноязыка. Не всегда в этом прочтении содержание фильма раскрывалось адекватно художественной форме. Часто недооценка собственно формы приводила к непониманию или неточному пониманию содержания. Одна из первых кинокритических дискуссий возникла в 1926 году в связи с выходом на экраны первого фильма режиссера Юрия Тарича «Крылья холопа». Для того чтобы выразить метущееся состояние царского холопа Никишки, попытавшегося осуществить свою дерзкую мечту взлететь на смастеренных крыльях с высоты Александровского собора, понадобился особый монтаж. Для этого в помощь молодому режиссеру была назначена опытный монтажер Эсфирь Шуб, увлекавшаяся параллельным монтажом, заимствованным из американских фильмов. Именно этот элемент художественного языка фильма был вменен «в вину» режиссеру-дебютанту. «В “Крыльях холопа" неуместно применен мелькающий рваный монтаж и подрезаны, слишком укорочены сцены. Зритель не успевает вглядеться и не может освоиться с обстановкой действия. Это буквально режет стиль постановки и подрывает смысл исторической картины...» (Hersonskiy 1965).На самом деле именно за счет монтажа было передано самое главное: неспокойный, таящий в себе много страхов, неожиданных, не сулящих ничего хорошего поворотов, дух эпохи времен Ивана Грозного, а также изломанные, изувеченные судьбы людей, в том числе и одаренного мечтателя - одного из царских подданных. Такая же «критическая» участь постигла многие фильмы, стили, ставшие впоследствии подлинными художественными открытиями, опередившими свое время. Непонятым и непризнанным было искусство ФЭКСов. Особенно «досталось» знаменитой «Шинели» (реж. Г. Козинцев и Л. Трауберг). То, что представляло очевидную художественную ценность (актерская эксцентрика, экспрессионистский визуальный ряд, смелое движение кинокамеры), в рецензиях на фильм рассматривалось как некая вольная авторская выдумка, не поспособствовавшая раскрытию гоголевского смысла. «Авторы поставили себе задачу: вскрыть в художественной манере Гоголя причудливое перевоплощение реальности в фантастику...Увлеченные более всего фантастикой, они отошли от реализма Гоголя... Перед их глазами еще не открылась жизнь, они показывают паноптикум» (Hersonskiy 1965). «Смешение планов фантастики и быта представляется путаницей, резкая эксцентрическая трактовка путаницы не разъясняет... “Шинель” сделана как эксцентрический гротеск в сгущенных экспрессионистских тонах... Лента не захватывает» (Bleyman 1973).

В истории кинокритики были разные периоды. За радостно восторженным анонсированием первых кинопоказов последовал первые аналитические рецензии, поскольку 20-е годы минувшего столетия были временем становления киноязыка, который во многом предопределил становление аналитической кинокритики. Писатели, театральные критики, журналисты на страницах журналов «Маски», «Сине-фоно», «Пегас», «Кинефот», «Кино» писали о том, что у нового вида зрелища есть «соответствие ритму и темпу современности», что «огромна его просветительско-культурная роль», что его главная специфика - «движение и молчание» (Selezneva 1972). Публикации первых кинокритиков - М.Горького, Л.Андреева, А.Белого, И.Соколова, Г.Болтянского, Т.Циперовича, А.Топоркова - можно определить скорее как публицистические эссе. Им были свойственны открытая субъективность авторской позиции, яркий стиль, насыщенная образность. Это был тот самый знаменитый эйзенштейновский «общий план» критики, когда кинематограф рассматривался в целом, на фоне социокультурного контекста. Для такой позиции нужна была страстность. Первые критические выступления в прессе были похожи на манифесты. Неслучайно известный кинокритик М.Блейман так описывал свой творческий опыт тех лет: «Я был тогда не исследователем кинематографа, не историком, а полемистом и агитатором» (Bleyman 1973). Этот этап критического осмысления, а точнее - открытия и утверждения нового вида искусства, можно назвать манифестационным. Начиная с 30-х годов ХХ века, главным смыслообразующим центром в искусстве становится личность социально востребованного человека. В газетно-журнальной периодике фильмы рассматривались с точки зрения идейного воспитания «строителей нового общества». Методологическая база, предполагающая представление фильма как мировоззренческой художественно-коммуникативной системы, уступила место методической инструментальности по обозначению функций и задач произведения в конкретном историческом периоде. Главное, на что делался акцент в кинокритических публикациях, - идейная направленность и воспитательный эффект.Этот этап представления фильма в прессе можно назвать манифестационно-дидактическим.В 50-х годах достаточно четко определились два подхода в осмыслении фильма: индуктивно-эмпирический, на основе которого предпринимались попытки определить специфику киноискусства из самого киноискусства, и дедуктивный, позволявший раздвинуть рамки традиционных искусствоведческих методов и объяснить природу кинематографа, прежде всего, как специфической коммуникативной системы. Первый путь дал мощный толчок развитию кинокритики. Второй породил лингвоцентристские, социологические, информационные и другие концепции, востребованные в киноведении. Начиная с 60-х годов, в кинокритике заметно оживился интерес к проблемам целостности фильма. Эти проблемы, обозначенные несколькими десятилетиями ранее, теперь стали исследоваться на другом уровне с учетом усложнившейся эстетики фильма, с одной стороны, а с другой - с учетом снижающихся художественных критериев, когда фильм представлялся как «средство борьбы»: социальной, идеологической, морально-психологической. На первый план в кинокритике вышли такие темы, как кинообразность, специфика 
кино как вида искусства, целостность композиции фильма. Фильм рассматривался сквозь призму этих составляющих как исходных и центральных феноменов киноискусства. Такая методология была своевременна, поскольку как нельзя кстати подходила к восприятию и оценке выходившего на первый план в это десятилетие авторского кинематографа.В произведениях «авторского кинематографа» стали важны такие составляющие, как ритм, атмосфера, художественная детализация. Как только эти картины анализировались с точки зрения драматургии образа главного персонажа (либо персонажей), психологических характеристик, поведения, то фильм переставал существовать как художественное произведение. Так случилось со знаменитыми картинами «История Аси Клячиной, которая любила да не вышла замуж...», «Андрей Рублев», «Зеркало», «Жил певчий дрозд», «Мне 20 лет». Они были не приняты по причине неадекватности критического инструментария по отношению к стилистике новых художественных систем. По этой же причине не была достойно оценена и белорусская картина «Восточный коридор» (реж. В.Виноградов). Из единой, неделимой художественной целостности критики выделили только одну линию - фабульно-смысловую, не связав в один узел содержание и изысканную форму.Резкий кризис кинопроизводства и кинопроката начала-середины 90-х годов вызвал к жизни обилие информационных жанров. Взоры критиков были обращены к видеоновинкам и к репертуару кинофестивалей разного уровня, что способствовало появлению в прессе видеообзоров и репортажей с фестивалей, авторских аннотаций к немногочисленным отечественным и большому количеству новых зарубежных фильмов. С другой стороны, эта ситуация спровоцировала изменение параметров собственно кинокритики. Постепенно из аналитического вида творческой деятельности критика превращалась в информационно-публицистический. В 90-х годах обозначился поворот кинокритики в сторону киножурналистики.В начале XXI века критика утвердилась в статусе «потребляемой эстетической информации», поскольку, как писал Ролан Барт, «общество стало потреблять критические комментарии совершенно так же, как оно потребляет кинематографическую, романическую или песенную продукцию» (Барт, 1994). Критика стала частью рекламной кампании, которая является естественным элементом в цепи производственно-товарных отношений.

ОБЗОР ЛИТЕРАТУРЫ. Одной из первых научных работ на тему становления кино как особого вида зрелища, а вместе с тем и обзор первых упоминаний об этом виде досуга в газетах и журналах, была монография советского киноведа, кинокритика Н. Зоркой «На рубеже столетий: У истоков массового искусства в России в 1900-10 гг.» (М., 1976). Осмысление собственной кинокритической практики как вида творческо-аналитической деятельности представлено в сборнике критика Х.Херсонского «Страницы юности кино. Записки критика» (М.1965). Кинокритический опыт, запечатленный в мини-рецензиях, был в свое время представлен в сборниках М.Блеймана «О кино - свидетельские показания» (М., 1973), Н.Лебедева «Внимание: кинематограф!» (М., 1974), С.Васильева в Собрании сочинений в 3-х т. «Братья Васильевы» (М., 1982). Первый опыт рассмотрения методологических подходов в кинокритике был предложен классиками советского кино, кинорежиссерами С.Эйзенштейном, Вс. Пудовкиным, А.Довженко, Л.Кулешовым, бр. Васильевыми. Эволюция развития теории кино, составной частью которой является и кинокритика, была проанализирована в монографии Т.Селезневой «Киномысль 1920-х годов» (М., 1972). Кинокритика как важная часть развития киноискусства и необходимый элемент медиаконтента не раз становилась предметом исследований белорусского ученого, кинокритика Е.Л. Бондаревой («Время, экран, критика», - Минск, 1975; «Экран в разных измерениях» - Минск, 1983; «Освещение литературы и искусства в СМИ» - Минск, 2004). Кинокритика как часть медиакритики рассматривалась в исследовании А.П.Короченского «Пятая власть? Медиакритика в теории и практике журналистики» (Rostov 2003). Теоретико-методологические проблемы киноведения и кинокритики стали основой коллективной монографии «Кино: методология исследования» (М., 1984). Основы системно-целостного подхода в рассмотрении произведения киноискусства впервые были представлены в монографии Е.Левина «О художественном единстве фильма» (М., 1977). Концептуальные подходы к исследованию и представлению кино были проанализированы в сборнике статей «История кино: современный взгляд. Киноведение и критика» (М., 2004). Медиаформаты современной кинокритики подробно проанализированы в научной статье Я.И. Тяжлова «Актуальные формы медиатекстов, посвященных кино: жанровые и языковые тенденции» (ж-л «Медиалингвистика» № 2 (12), 2016. Сущностно-коммуникативные особенности представления фильма в прессе были рассмотрены в статьях американских авторов: Р. П. Кларк.« This is why we write stories» - URL:http://www.poynter.org/2015/this-is-why-we-write-stories/367477/, Making Hard Facts Easy Reading. 1984. URL: http://cdn.nycitynewsservice.com/blogs.dir/422/files/2014/02/ MakingHardFactsEasyReading.pdf.; РичардМаркус «And Reviewer: A Difference In Intent / Richard Marcus - URL: http://blogcritics.org/critic-and-reviewer-a-difference-in/.

МЕТОДЫ ИССЛЕДОВАНИЯ. При анализе смысловых доминант кино и кинокритики был апробированкультурологический метод, позволивший оценить как представляемый кинофакт, так и рефлексию в кинокритическом тексте. Анализ функциональных особенностей кинокритических публикаций, посвященных разным вопросам киноискусства, предполагает обращение к методам системно-целостного анализа и киногерменевтики, позволяющим выявить синтез содержания и формы, авторской мировоззренческой основы и особенностей авторского киноязыка. Наиболее полный анализ текстов печатных СМИ возможен при использовании метода контент-анализа, помогающего раскрыть и систематизировать содержательнотематическое поле медиатекстов, посвященных киноискусству. 
РЕЗУЛЬТАТЫ И ДИСКУССИЯ. Всовременной кинокритической практике наблюдаются тенденции умаления некоторых неоднозначных смысловых доминант, обозначенных в талантливых фильмах нынешнего времени.Кинокритика, реализующая аксиологическо-познавательную функцию, традиционно предлагала моделирование определенных ценностных отношений, которые всегда были приоритетными. В современной медиапрактике анализ собственно содержательных смыслов подменяется представлением авторских стратегий. Например, фильм «Неоновый демон» одного из самых заметных в мировом кинопространстве режиссеров Николаса ВиндингаРефна вызвал даже у профессиональной публики неоднозначное отношение.Тяга к насилию как разновидности психического отклонения всегда была главным предметом творчества эпатажного датчанина и в «Неоновом демоне» достигла апогея: весь фильм - сублимация авторских вожделений, своего рода сексуальное самоудовлетворение, которое художник сделал прибыльным бизнесом.Несмотря на внешнюю визуальную броскость, содержательный посыл фильма деструктивен. В рецензиях некоторых журналистов, критиков была заметна позиция представить творение скандального режиссера как новое авторское слово, должное привлечь внимание («Неоновый демон»- это самая настоящая сказка. Да, тут есть оральный секс с ножом, некрофилия, каннибализм, попытка лесбийского акта и намеки на педофилию, но ничто из этого не принижает всю сказочность происходящего... Он (фильм) о Красоте» (Vadim Bogdanov 2016); «...nустота «Неонового демона» способна лишить дара речи любого критика-интерпретатора: осмысленному прочтению фильма ...nрепятствует его вызывающее, демонически-претенциозное пижонство» (Василий Корецкий, 2016); «Рефн дает фору любому неповоротливому классику тем, как умело и современно обращается с материалом. Он шутит там, где другие серьезны, льет литры крови и рассыпает блестки, пока фестивальные старожильл напьщенно надувают щеки и играют в занимательную философию» (Anna Efremenko 2016). В 2018 году на экраны вышел новый фильм другого скандального режиссера Ларса фон Триера «Дом, который построил Джек», главный герой которого - маньяк-убийца. Смыслом жизни и основной ценностью несостоявшегося архитектора является та «красота», которая проступает сквозь формы «дома», составленного из тел убитых им людей. Образ главного героя фильма так представляется в современных рецензиях: «По счастью, у Дюека есть хобби - он убивает. И если с домом не ладится, то с убийствами складывается куда лучше. Настолько, что Джек начинает позиционировать свою деятельность как своего рода вид изящных искусств, постоянно отвлекаясь набесконечные цитаты, параллельные сюжеты и исторические реминисцениии. Джек размылияяет о достижениях Адольфа Гитлера...и сравнивает с ними собственное «искусство». Джек находит достижения тоталитарных режимов вобласти массовых убийств преступно недооценёнными в художественной плоскости и очень хочет вписать себя в этот ряд «великих твориов» (Dmitriy Nazarov 2018); «От первого детского опыта (удаления утенку лапки пассатижами) до расстрела детей и отрезания женских грудей он проходит путь изощренного эстета, наращивающего художественную мощь и большой стиль. Раскроив встреченной на дороге идиотке... череп домкратом, герой чувствует, что поддался эмоции и сработал грубо. Далее он будет действовать более изысканно» (Andrey Plahov 2018). Подробная, талантливая рецензия на фильм была написана одним из лидеров российской кинокритики, главным редактором журнала «Искусство кино» Антоном Долиным - «Записки из мертвого дома» (2018), где анализируются многообразные составляющие фильма: эстетические, философские, живописные, мифологические, кинематографические, культурно-стилевые. Смысловым итогом этой рецензии стало авторское заключение: «B катарсис, исцеление, искупление, хэппи энд сегодняшний фон Триер верит не больще, чем в победу ягненка над тигром» (Anton Dolin 2018).

ЗАКЛЮЧЕНИЕ. Формы представления фильма в современной кинокритике многообразны: от рекомендательных списков до аналитических обзоров. Несмотря на то что некоторые авторы уверяют, что «в ситуации перенасыщения информацией аудиторией востребована не столько оценка фильма, базирующаяся на подробном анализе, сколько рекомендация, выраженная количественными характеристиками: мнение большинства, бюджет, место в рейтинге, топе, маркеры реляционных элементов» (Тяжлов, 2016), одной из самых насущных эстетических потребностей современного человека (потребителя) является потребность в раскрытии, осознании важных смыслов, запечатленных в произведении искусства вообще, киноискусства в частности. Важную роль в этом процессе познания играет «объяснительная» кинокритика.

\section{LIST OF REFERENCES}

Barthes R. (1994) Izbrannyeraboty. Semiotika. Poetica [Selected Works. Semiotics. Poetics ] Moskva: Progress. 616 p. Bleiman M. (1973) O kino - svidetelskiepokazania [About the movie - witnesses] Moskva: Iskusstvo. 588 p.

Bogdanov Vadim. «Neonovyi demon» - brilliant v more stekla [«Neon demon» - a diamond in the sea of glass].http://www.newlookmedia.ru/?p=51445 [30.08.2016].

Celezneva T. (1972) Kinomysl 1920-hgodov [Kinomysl 1920s].- Leningrad.: Iskusstvo.

Dolin Anton. Zapiskiizmertvogodoma. (2018). [Notes from the dead house]. Iskusstvokino. № 7/8, 2018, $174-189$.

Efremenko Anna. «Neonovyi demon»: 8 iz 10. V minskiyprokatvyshelsamyiskandalnyi film Kann [«The Neon demon»: 8 from 10. The most scandalous film Cannes was released in Minsk]

http://afisha.tut.by/news/reviews/505953.html [30.08.2016].

Khersonskiy Chrysanf. (1965) Stranitcyyunostikino [Cinema youth pages] Moskva: Isdatelstvo «Iskusstvo».276 p .

Kino: metodologiaissledovania (1984) [Cinema: research methodology ]Moskva: Iskusstvo. 
KoretckiyVasiliy. Moguchayasuchka. Neonovyi demon NikolasaVindingaRefna: pochemyetozdorovo e vechno [Mighty bitch. «The Neon demon» Nikolas VindingRefn: Why it is healthy and everly». https://www.colta.ru/articles/cinema/11983-moguchaya-suchka [08.09.2016]

Nazarov Dmitriy. «Spas nakrovi - arhitekturnyianaliz «Doma, kotoryipostroil Jack» [Savior on spilled blood is an architectural analysis of the «House that Jack built»] http://kinochannel.ru/digest/spas-na-krovi-arhitekturnyj-analizdoma-kotoryj-postroil-dzhek/[20.12.2018].

Plahov Andrey. Gimnkrysinymkorolyam [Anthem rat kings] https://www.kommersant.ru/doc/3821374 ( 10.12.2018).

Tiazhlov I. Aktualnyeformymediatekstov, posviashchennyhkino: janrovye I yazykovyetendencii [Topical forms of media texts dedicated to the cinema: genre and linguistic trends] https://medialing.ru/aktualnye-formy-mediatekstovposvyashchennyh-kino-zhanrovye-i-yazykovye-tendencii/ ( 02.01.2018).

Zorkaya N.M. (1976) Na rubezhestoletiy. U istokovmassovogoiskusstva v Rosii 1900-1910 godov [At the turn of the century. At the origins of mass art in Russia in 1900-1910] Moskva: Nauka. 301 p.

\title{
For citation:
}

Sayenkova-Melnitskaya, L. (2019) CINEMA AND FILM CRITIC: MEDIAPRACTICS IN DISCOVERING OF THE MEAN DOMINANT. International Scientific-Pedagogical Organization of Philologists “WEST-EAST ” (ISPOP). Scientific Journal WEST-EAST. Vol 1/1 N1 (October, 2019). pp. 70-74. doi:

\section{Для цитирования:}

Саенкова-Мельницкая, Л. (2019) КИНО И КИНОКРИТИКА: МЕДИАПРАКТИКИ В РАСКРЫТИ СМЫСЛОВЫХ ДОМИНАНТ // International Scientific-Pedagogical Organization of Philologists “WEST-EAST" (ISPOP) . Scientific Journal WEST-EAST. Vol 1/1 N1 (October, 2019). C. 70-74. doi:

Information about the author: Ludmila Sayenkova-Melnitskaya -Candidat of filological Sciences, associate Professor, head of the Department of literary and artistic criticism of the faculty of journalism of Belorussian State University.

e-mail: sayenkova@gmail.com

Сведения об авторе: Людмила Саенкова-Мельницкая -кандидат филологических наук, доцент, заведующий кафедрой литературно-художественной критики факультета журналистики Белорусского государственного университета.

e-mail: sayenkova@gmail.com

Manuscript received: 05/25/2019 Accepted for publication: 09/23/2019

DOI:

\section{ORTHOGRAPHIC VARIANTS OF THE LATEST ENGLISH BORROWINGS IN RUSSIA MEDIA DISCOURSE}

\author{
Anna Romanik \\ Doctor of Philosophy in Linguistics \\ Institute of East Slavic Philology, \\ University of Bialystok \\ (Bialystok, Poland) \\ e-mail: aniaromanik8@wp.pl
}

\begin{abstract}
This article is devoted to the issue of variability of writing of English borrowings in usual practice in contemporary Russian language. Fluctuations in writing of anglicisms in the mass media is a current dynamic phenomenon in orthography and graphics of the Russian language, which today is an important problem of normative linguistics. The aim of the author is to analyze the writing doublets of the newest English loanwords functioning in the mass media language and to define the problems caused by fluctuations in the spelling of borrowings. An important task in this study is also to identify the reasons and consequences of instability of the examined individuals. The empirical material was selected from "Словарьновейшихиностранныхслов" by Shagalova (Moscow 2017), that contains 3500 borrowings illustrating the linguistic reality of the contemporary media. In the course of the research the method of material excerption and method of synchronous analysis of heterogeneous notations of English origin were applied.
\end{abstract}

Key-words: anglicism, media discourse, norm, orthography, variability 